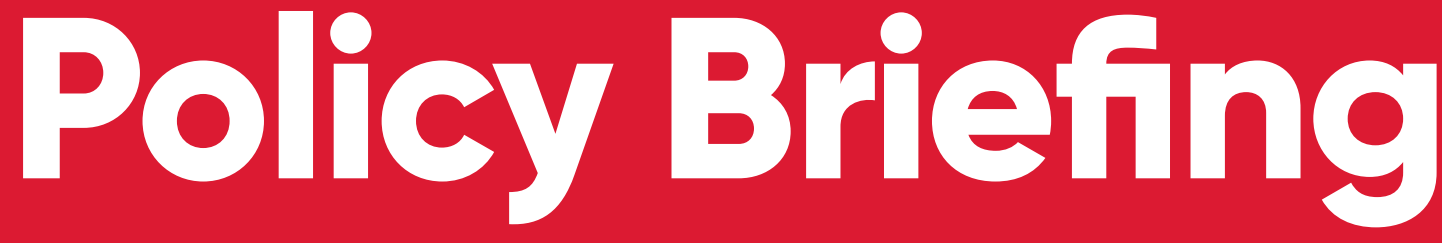

\title{
Student Wellbeing in Contexts of Protracted
}

\section{Violent Conflict}

In contexts of protracted violent conflict, school environments play a key role in children's psychological, social, and emotional wellbeing. Research by the REALISE education project in the Democratic Republic of the Congo (DRC) provides a better understanding of how violent conflict penetrates schools; the relationship between school staff, students, parents, and the local community; and the role of children's social entourage. It identifies key considerations for education projects operating in these contexts and how they can best support the wellbeing of children, including those who are extremely isolated or experience marginalisation on the basis of gender or minority status.

\section{Key messages}

- Education interventions in fragile and conflict-affected contexts should prioritise children's mental health and wellbeing.

- Mental health and wellbeing interventions should be gender sensitive.

- Children in situations of acute social isolation, hard to reach through conventional channels, should be targeted by specific programme components.

- Education interventions should actively seek to target prejudice and discrimination in the school environment, as these negatively affect children's mental health and can significantly erode the protective role of schools.

ids.ac.uk
30

Increased school access for children from marginalised groups can be beneficial but can also expose them to discrimination, pressure, shame, and bullying.

Gauthier Marchais, 


\section{Pressure and discrimination in the school environment}

Pressure and discrimination can have negative impacts on students' learning and wellbeing. In contexts of violent conflict, discrimination in the school environment may be a particular concern, as it can reflect broader processes of marginalisation that underpin the conflict itself.

The research found evidence of routine discrimination against students from the Twa ethnic minority, which was prevalent in the discourses and practices of students, parents, and even school staff. These reflect longstanding forms of discrimination prevalent in the Congolese education system and society. Evidence of gendered discriminatory practices was also found, particularly around menstrual hygiene, which can generate significant psychological pressure for girls in the school environment. This was starker for Twa girls and may partially explain their significantly lower enrolment rates.

The enforcement of school fees, in particular the threat of being expelled by school staff, generated significant pressure for students. It was common for students unable to pay school fees to make payments 'in kind' instead, usually by working in the fields of school staff. This can impose a significant physical and mental burden on students and reinforce inequalities, as students with lower incomes face more difficult studying conditions. While the Gratuité policy, implemented in September 2019, officially abolished school fees, such in-kind payments have partially continued, particularly in underfunded schools.

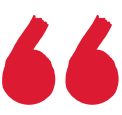

\section{Daily pressure, discrimination, and violence in the school environment impose a significant burden on children's psychological and socio-emotional wellbeing.}

\section{Violent conflict in the school environment}

Beyond direct attacks by armed actors on schools and students, multiple forms of violence, threats, and coercion can occur within the school environment, which are often gendered. The atmosphere of violent conflict can also exacerbate tensions within the school environment and cause them to escalate into physical violence. Social polarisation and generalised mistrust, which are characteristic of militarised societies, penetrate the school environment and create an atmosphere of fear and tension that can have significant psychological effects on children - even after armed conflict ends.

\section{The burden of conflict on children's wellbeing}

Daily pressure, discrimination, and violence in the school environment impose a significant burden on children's psychological and socio-emotional wellbeing. Our survey found evidence of significant levels of depression among children in Tanganyika, which confirms that students in conflict-affected contexts face considerable psychological and socio-emotional challenges. Further analyses identify those worst affected, including out-of-school children who display higher depressive symptoms and behavioural problems. Girls report slightly higher depressive symptoms and emotional problems than boys, and Twa children show significantly higher levels of depression and lower levels of pro-social behaviour than non-Twa children. This reflects the structural marginalisation of Twa populations, their higher exposure to conflict-related violence and to discriminatory practices in the school environment.

Regarding the role of social networks and relationships, students from households with smaller social networks report higher levels of depression and lower levels of socio-emotional wellbeing. This points to the detrimental effect of social isolation, which can be particularly acute for children 
exposed to violent conflict. It supports the idea that children's social entourage plays a crucial role in alleviating the negative impact of violent conflict on their wellbeing, and also the benefit of interventions that build protective social entourage around children and develop school and parent communities around the school.

\section{'Schools as safe spaces'? Addressing 'ethnic' discrimination}

'Schools as safe spaces' has emerged as a key approach in the field of education in emergencies and entails socio-emotional learning, conflict-sensitive education, or peace education interventions. REALISE is not an education in emergencies project but the evidence suggests that it is crucial to pay close attention to the relationship between access and protection, and the role of 'communities' in creating safe spaces.

First, increasing access to school for children from marginalised groups can be beneficial but it can also expose them to discrimination, pressure, shame, and bullying. Teachers can have discriminatory discourses and practices, and even carry out violence or exploitation against students.

Second, the results challenge assumptions behind the role of communities in contributing to making schools 'safe spaces'. 'Communities' are widely regarded as a key supporting entity in education interventions. REALISE, for example, has specific community interventions, such as Citizen Voice and Action and Sexual and Reproductive Health groups, and the concept of community forms an essential part of the project's Theory of Change. The concept of community, however, is often used generically without consideration of the deep changes induced by violent conflict. Projects should therefore seek to unpack these communities to understand how violence penetrates schools and the social environment of children.

Third, enhancing the wellbeing of children requires special attention toward children suffering from trauma. Education interventions

\section{Approaches that rely on principles of 'leave no one behind' and aim to address extreme marginalisation must develop tools to proactively identify and support children in situations of extreme social isolation, instead of relying on school- based interventions.}

are increasingly seeking to incorporate the question of psychological trauma in their approach. The REALISE project, for example, facilitated the training of teachers in psychological first aid. However, it is important to consider the limited scope teachers have to deal with such issues in addition to their professional obligations, and the fact that teachers may be experiencing trauma themselves. Moreover, families remain the first entry point to support traumatised children but are not necessarily equipped to help them. Thus, in addition to school staff, projects should seek to equip families and the social entourage of children with tools to address trauma and depression.

Finally, the challenges of interventions that seek to reinforce the protective entourage of children are particularly acute for children in situations of extreme social isolation, who cannot be reached by established channels. Approaches that rely on principles of 'leave no one behind' and aim to address extreme marginalisation must develop tools to proactively identify and support these children instead of relying on school-based interventions. This is also relevant in contexts not affected by violent conflict, and in the context of school closures and increased social isolation of children due to the Covid-19 pandemic. 


\section{Policy recommendations}

\section{Develop tools for a better understanding} of violence in and around the school

environment. Education programmes

should consider the school environment

in its wider social context and better understand the ways in which violence penetrates the school environment.

2. Develop tools to tackle extreme social isolation, including outside of the school environment. In violent contexts, education interventions can miss the most vulnerable children, in particular socially isolated children who are often out of school. Proactive measures to identify and target children in situations of extreme social isolation can be reinforced.

\section{Help parents help their children.}

Parents and carers of children play a central role in their psychological and socio-emotional wellbeing. Education programmes can help equip parents with tools for dealing with trauma, depression, and isolation.
4. Add conditions of access as an outcome indicator. 'Increased access' to school is insufficient to support the psychological and socio-emotional wellbeing of children in conflict-affected contexts, as they can be subjected to pressure and violence in the school environment. Projects should reinforce objectives around the conditions and experience of schooling.

\section{Address discrimination in schools.}

Discrimination based on student identity is widespread in polarised social contexts. Education programmes should apply the range of Gender Equality and Social Inclusion and Teacher Professional Development tools to address discrimination. It can involve work on curricula, and teacher training on awareness of the prejudice they can spread and how to address questions around historical forms of marginalisation. The Do-No-Harm principle should always apply, which implies that discrimination ought only to be addressed when it can be established that such practices will not reinforce societal fault lines.
Institute of Development Studies, Library Road, Brighton BN1 9RE, United Kingdom +44 (0)1273 606261 ids.ac.uk IDS is a charitable company limited by guarantee and registered in England. Charity Registration Number 306371. Charitable Company Number 877338.

\section{Further reading}

Higgins, S. and Novelli, M. (2020) 'Rethinking Peace Education: A Cultural Political Economy Approach', Comparative Education Review 64.1: 1-20

Marchais, G. et al. (2021, forthcoming) Violent Conflict and the Socio-Emotional Wellbeing of Students in the Democratic Republic of Congo, IDS Working Paper

Marchais, G. et al. (2021) Marginalisation from Education in Conflict-Affected Contexts: Learning from Tanganyika and Ituri in the DR Congo, IDS Working Paper 544, Brighton: Institute of Development Studies, DOI: 10.19088/IDS.2021.017 Moriarty, K. (2018) Safe Schools: The Hidden Crisis. A Framework for Action to Deliver Safe, Non-violent, Inclusive and Effective Learning Environments, London: Theirworld
This IDS Policy Briefing was written by Gauthier Marchais (IDS), Sweta Gupta (IDS) and Cyril Brandt (IDS and IOB Antwerp), edited by Sophie Robinson (IDS) and supported by Deborah West (IDS). It was produced as part of the Girls' Education Challenge REALISE education project funded by the Foreign, Commonwealth \& Development Office (FCDO) as part of the Girls' Education Challenge and led by Save the Children, in partnership with World Vision International.

The opinions expressed are those of the authors and do not necessarily reflect the views or policies of IDS or the UK government.

(c) Institute of Development Studies 2021.

cc (i) This is an Open Access briefing distributed under the terms of the Creative Commons Attribution 4.0 International licence (CC BY), which permits unrestricted use, distribution, and reproduction in any medium, provided the original authors and source are credited and any modifications or adaptations are indicated. ISSN 1479-974X DOI: 10.19088/IDS.2021.055 